${ }^{1}$ WSL Swiss Federal Research Institute, Lausanne, Switzerland

${ }^{2}$ EPFL Swiss Federal Institute of Technology at Lausanne, Lausanne, Switzerland

\title{
Recent climate change: Rethinking drought in the context of Forest Fire Research in Ticino, South of Switzerland
}

\author{
M. Reinhard ${ }^{1}$, M. Rebetez ${ }^{1}$, and R. Schlaepfer ${ }^{2}$ \\ With 7 Figures \\ Received July 28, 2004; revised December 3, 2004; accepted December 19, 2004 \\ Published online March 31, 2005 (C) Springer-Verlag 2005
}

\begin{abstract}
Summary
We analyse trends over the past 32 years in drought variables in the context of forest fire research and climate change in Ticino, Southern Switzerland. January to April and in particular the month of March have become drier. This is the time of the year when forest fires are most frequent. Our results show an increasing trend in all climatic variables favourable to drought and forest fires, including the length of episodes without precipitation, sunshine duration and temperature, and a decrease in relative humidity. The only exception is the number of "foehn" days, which have not significantly increased.
\end{abstract}

Acronyms: BFDS, Broad Fire Development Season; CFDS, Critical Fire Development Season.

\section{Introduction}

Concern about the likely impact of global climate and environmental changes has grown stronger within the scientific community in recent decades. Changes in precipitation are expected to occur with climate warming (IPCC, 1995, 2001), with an overall global increase, but varying regional patterns (IPCC, 1998), including a decrease in Southern Europe (IPCC, 2001). Additionally, changes are expected, or have already been observed in temporal distribution of precipitation, as in the European Alps (Frei et al., 1999). Research within the framework of projects such as STARDEX (Statistical and Regional dynamical Downscaling of Extremes in Europe) showed changes in precipitation patterns in the Swiss Alps, and in particular an increased number of extreme events in autumn and winter (Schmidli and Frei, 2003). The same study indicated a significant decrease in precipitation frequency, particularly in spring, for the southern Alps of Switzerland.

Drought is a recurrent feature of climate. Nevertheless, research often stumbles over its definition and there is no simple and unambiguous definition of drought universally accepted (Barry and Chorley, 2003; Wilhite, 2000). Authors traditionally distinguish between meteorological, sociological, agricultural and hydrological droughts (Bryant, 2001; Wilhite, 2000). The definition of drought depends primarily on the purpose of the assessment and, secondarily, on the area assessed and its particular topographic or climatic features (Barry and Chorley, 2003). Forest fire dynamics are strongly influenced by climate, which determines fire prone conditions (Johnson, 1992). Palaeoclimatic investigations have confirmed that relationship (Tinner et al., 1998, 1999; Meyer et al., 1995). Many studies highlighted the likely impacts of climate change on fire occurrence and discuss forest fires in the light of carbon 
emissions and destruction of carbon sinks (Gillett et al., 2004; Amiro et al., 2001; Flannigan et al., 2000). In this article, we address drought in the context of forest fires in Ticino, Southern Switzerland, and consider various climatic variables influencing on the state of available fuel in the forests.

Switzerland is not a place commonly associated with forest fires, except on the Southern Alpine slopes, where forest fires occur every year. In this area fires devastate forests, which fulfil important protective functions (Conedera et al., 1996, 1997) for human settlements and infrastructures such as highway and railway networks on one of Europe's most important NorthSouth roadlinks (San Gothard road). Canton Ticino is the most affected state in Switzerland. Winter and the beginning of spring are the periods of the year with least precipitation in this area (Rebetez, 1999), and the end of winter and early spring are when most forest fires occur (Conedera et al., 1996, 1997).

We analyse the occurrence of drought in Ticino by assessing the most relevant climatic variables and discuss the role of temperature, relative humidity, wind and sunshine duration in defining fire prone conditions. We also studied trends in these variables in order to see to what extent they may be linked to climatic change. We did not use drought indexes (e.g. Palmer Drought Index) in this paper, firstly because we do not have effective measures of ground dryness and, secondly, because Ticino is small and its topographical features are particularly heterogeneous due to its mountainous relief. We focussed on the climatic context leading to fire-prone conditions rather than using the fire events themselves because most forest fires in Ticino are anthropogenically triggered (Conedera et al., 1996).

\section{Data}

Data from two MeteoSwiss meteorological stations were used, namely Lugano and Locarno (Fig. 1), covering the period from 1971 to 2003. These stations have recorded meteorological variables since the beginning of the 20th century, but changes in equipment and location were made in Lugano in 1971 so that, for some variables, the earlier data may be inappropriate. The 1971-2003 period allows the data from two meteorological stations to be compared consistently.

We analysed drought patterns using the mean monthly values of the following meteorological variables: minimum and maximum temperatures, precipitation, relative humidity at $7 \mathrm{am}, 1 \mathrm{pm}$,

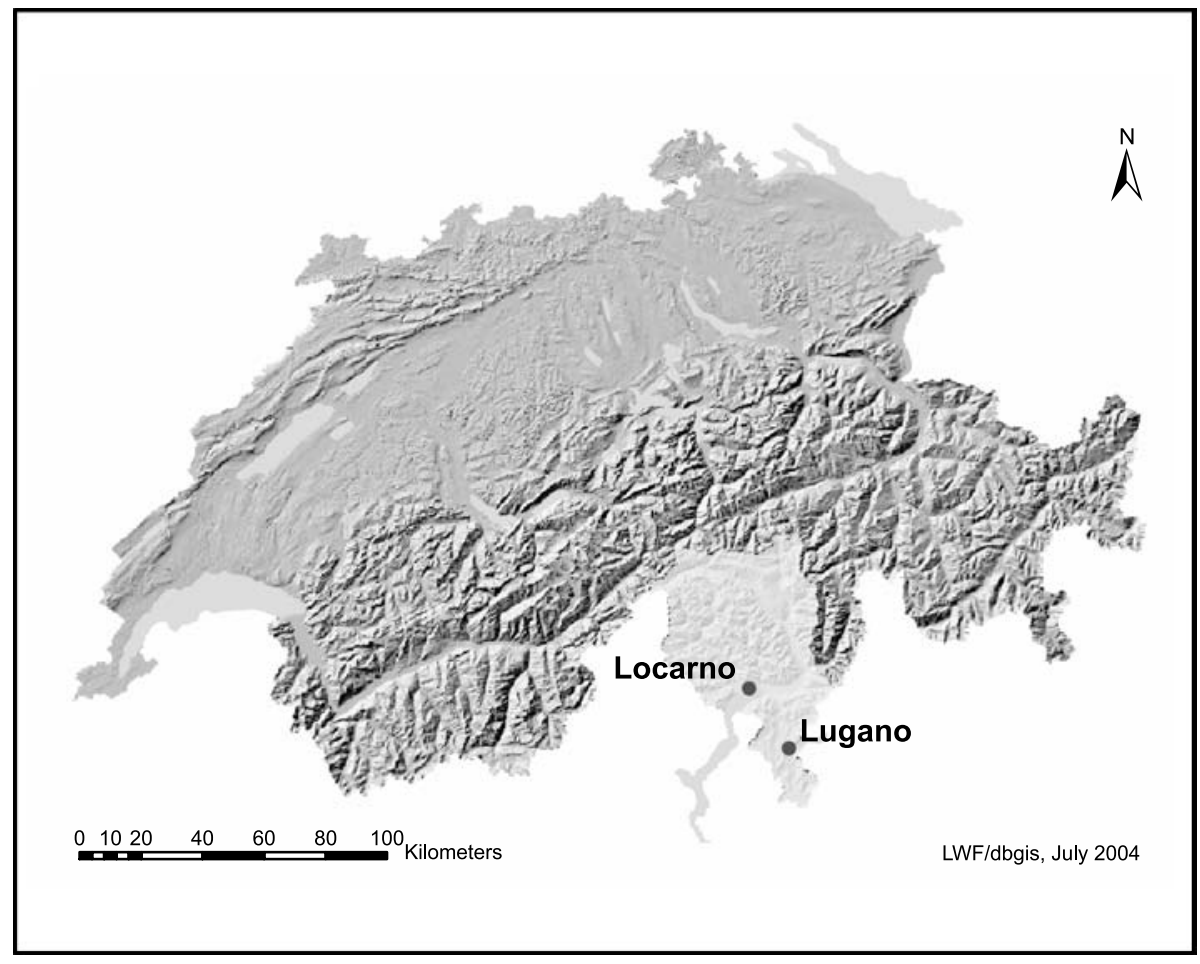

Fig. 1. Map of Switzerland with the location of the meteorological stations 
$7 \mathrm{pm}$, and sunshine duration in hours (absolute duration) and percentage (relative duration). We also considered wind as it may affect how dry potential fuels available in the forests are. In Ticino, the effect is particularly strong when Foehn winds occur. The Foehn is a warm, dry wind blowing southwards in the inner Alpine valleys when humid air masses are blocked against the northern Alpine slopes. We recorded Foehn wind on a monthly basis. Foehn data, however, were only taken from one station as the Foehn depends on large synoptic pressure systems developing over the Alps and affects the whole region indiscriminately. In this study, Foehn events have been defined as all situations with less than $35 \%$ relative humidity and wind direction ranging between $330^{\circ}$ and $40^{\circ}$ at the Lugano Station. We did not consider evapotranspiration because most forest fires in Ticino occur in winter, when it is low.

As forest fires mostly occur in March and April (Fig. 2), we defined the November to April period as the Broad Fire Development Season (BFDS) and the January to April period as the Critical Fire Development Season (CFDS). We used the conventional definition of seasons by MeteoSwiss for all seasons: winter being defined as the period including the months December to February, spring the months March to May, summer the months June to August and Autumn the period from September to November. The Forest Fire Database used for Fig. 2 was provided by WSL Sottostazione Sud delle Alpi. All meteorological data were taken from MeteoSwiss database.

\section{Fire Occurrences per Month (1971-2002)}

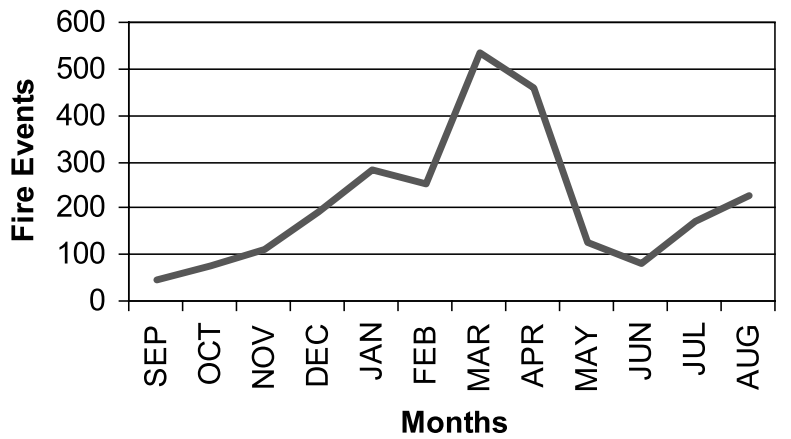

Fig. 2. Monthly total number of fire events from 1971 to 2003
Temporal autocorrelation of residuals for all trend analyses were calculated in order to provide a basis for the significance tests. Since the data do not autocorrelate, classical tests could be used. In the text, highly significant means $\mathrm{p}<0.01$ or lower and significant $\mathrm{p}<0.05$.

\section{Results}

Minimum temperatures have increased in a highly significant manner over the past three decades at both locations. Annual minimum temperatures have increased by $0.53{ }^{\circ} \mathrm{C}$ per decade in Lugano and $0.47^{\circ} \mathrm{C}$ in Locarno. Warming in minimum temperatures has been highly significant in all seasons except winter. The increase in spring has been greater than that in annual values in both Lugano $\left(+0.71{ }^{\circ} \mathrm{C}\right)$ and Locarno $\left(+0.73^{\circ} \mathrm{C}\right)$. May (Fig. 3) exhibits the largest increase, with $+0.98^{\circ} \mathrm{C}$ per decade in Lugano and $+0.9^{\circ} \mathrm{C}$ in Locarno. BFDS trends are highly significant with increases of $0.37^{\circ} \mathrm{C}$ per decade in Lugano and $0.31^{\circ} \mathrm{C}$ in Locarno. The March increase is greater than the annual increase with a highly significant increase of $+0.74{ }^{\circ} \mathrm{C}$ per decade in Lugano and $+0.85^{\circ} \mathrm{C}$ in Locarno. April, the most fire-prone month, exhibits a highly significant increase of $+0.41{ }^{\circ} \mathrm{C}$ per decade in Lugano, and a significant increase of $+0.43^{\circ} \mathrm{C}$ in Locarno.

There was a highly significant increase in maximum annual temperatures at both stations of $+0.41{ }^{\circ} \mathrm{C}$ per decade in Lugano and $+0.46^{\circ} \mathrm{C}$ in Locarno. There were, however, no significant trends in maximum temperatures in autumn and winter. The largest increases were again in spring with a highly significant $+0.90{ }^{\circ} \mathrm{C}$ per decade in Locarno and $+0.71{ }^{\circ} \mathrm{C}$ in Lugano. This is due particularly to the marked increases in March (Fig. 4) of $+1.37^{\circ} \mathrm{C}$ per decade in Locarno and $+1.09^{\circ} \mathrm{C}$ in Lugano. The fire month April, however, showed no significant trend. The increase in the CFDS were highly significant at $+0.63^{\circ} \mathrm{C}$ per decade in Locarno and $+0.49^{\circ} \mathrm{C}$ in Lugano.

Both minimum and maximum temperatures began to increase markedly in the mid 1980s, while the 1970s and the first part of the 1980s were quite stable.

The overall precipitation exhibited no significant annual trend, which is consistent with previous findings (Rebetez, 1999; Schmidli and 
Minimum Temperatures in May (1971-2003)

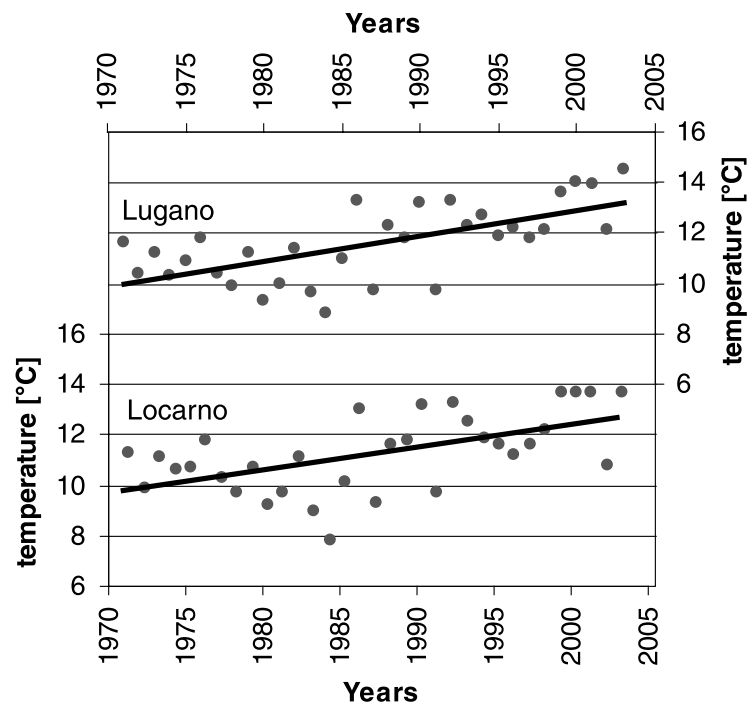

Maximum Temperatures in March (1971-2003)

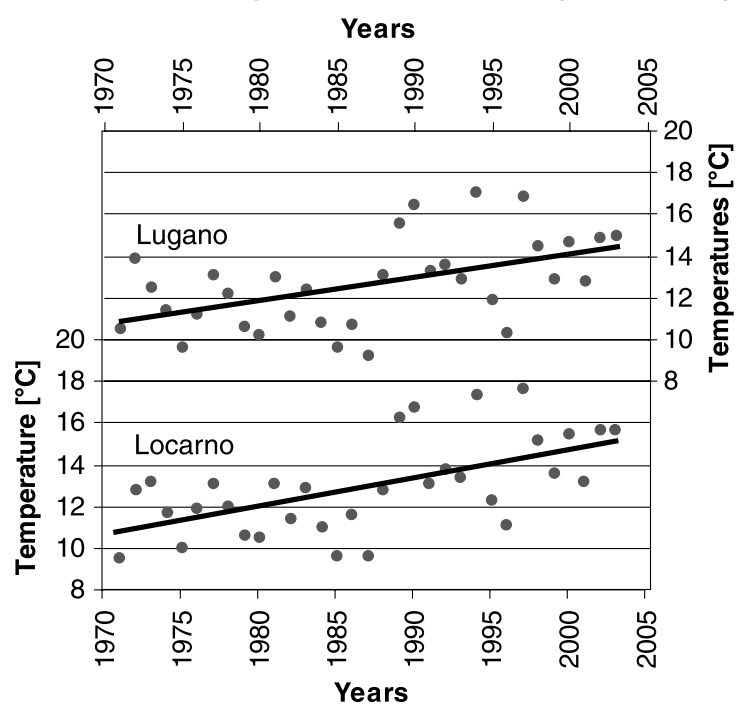

$R^{2}=0.41$

trend $=+1.0^{\circ} \mathrm{C} /$ decade

$p<0.001$

$\mathrm{R}^{2}=0.32$

trend $=+1.0^{\circ} \mathrm{C} /$ decade

$\mathrm{p}<0.001$
$\mathrm{R}^{2}=0.25$

trend $=+1.1^{\circ} \mathrm{C} /$ decade

$\mathrm{p}=0.003$

$\mathrm{R}^{2}=0.34$

trend $=+1.4^{\circ} \mathrm{C} /$ decade

$\mathrm{p}<0.001$
Fig. 3. Mean daily minimum temperatures in May in Locarno and Lugano
Fig. 4. Mean daily maximum temperatures in March in Locarno and Lugano
Frei, 2003). In Lugano, however, there was a significant trend of $-21.3 \mathrm{~mm}$ per decade in summer and $-14.9 \mathrm{~mm}$ in winter. The CFDS in Lugano decreased $-16.6 \mathrm{~mm}$ per decade. During the same period, precipitation decreased significantly, particularly in March with $-37.4 \mathrm{~mm}$ per decade (Table 1). The length and frequency of the episodes with no or very little precipitation (i.e. at least 60 days with a maximum of $10 \mathrm{~mm}$, Rebetez, 1999) have increased in both Lugano and Locarno (Fig. 5). All these dry episodes to date have been between October and April.

Relative humidity (Fig. 6) has decreased considerably on monthly and seasonal basis. Lugano exhibits a mean annual negative trend of $-3.1 \%$ per decade and Locarno $-2.1 \%$. The morning value ( 7 am measure) in Lugano dropped very significantly for all seasons and all months with the exception of November. Locarno had highly significant trends for March $(-4.2 \%)$. Winter and spring decreased significantly. All three daily measures ( $7 \mathrm{am}, 1 \mathrm{pm}, 7 \mathrm{pm}$ ) for CFDS have decreased highly significantly at both stations.

There was a significant positive trend in sunshine duration at Lugano of +8.6 hours $(+2.4 \%)$ in summer and in winter of +12.2 hours $(+3.6 \%)$. Absolute sunshine duration during CFDS significantly increased (highly significant) 


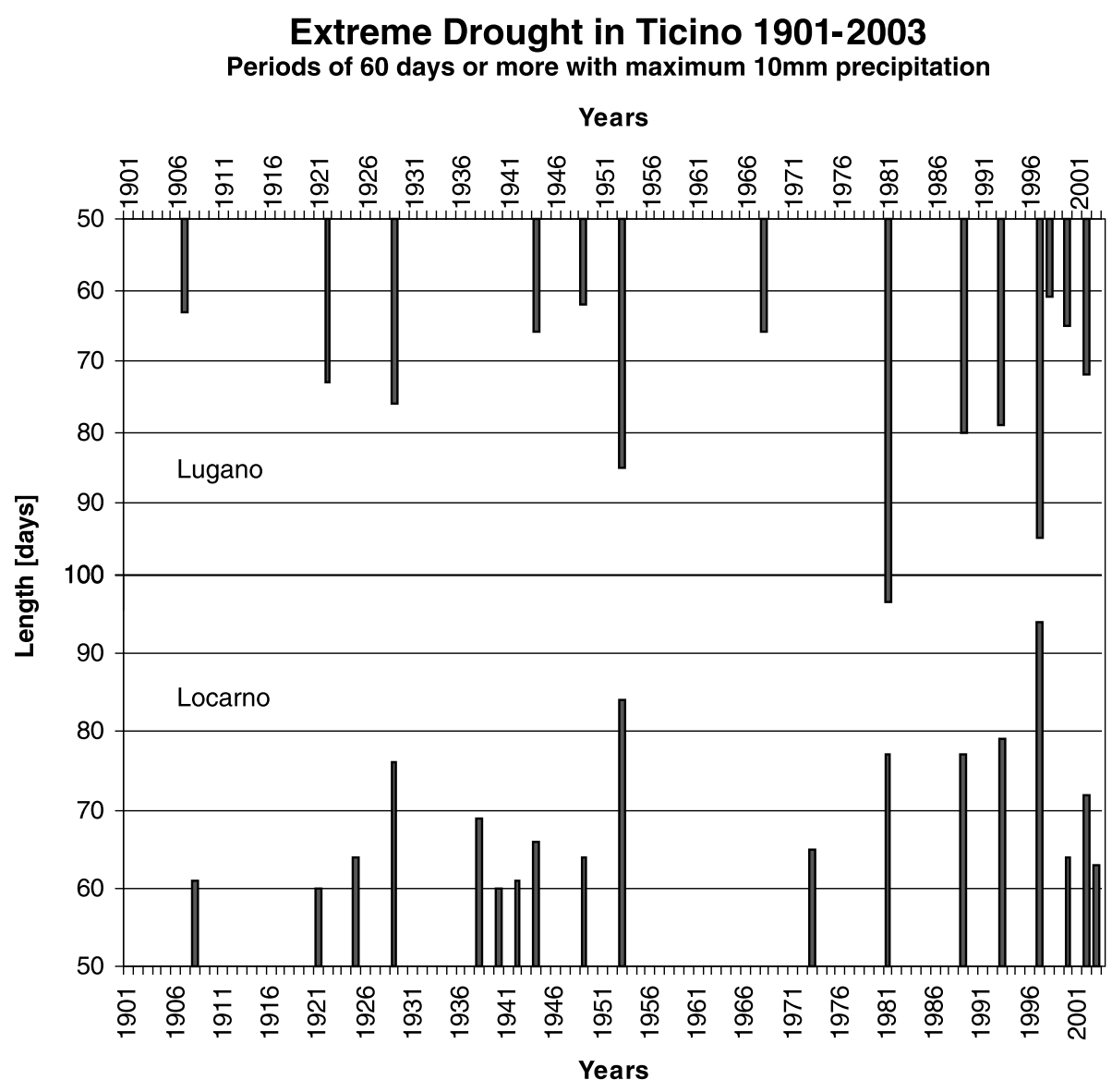

Fig. 5. Length of episodes of minimum 60 days with $10 \mathrm{~mm}$ precipitation or less

Relative Humidity at 7am in March (1971-2003)

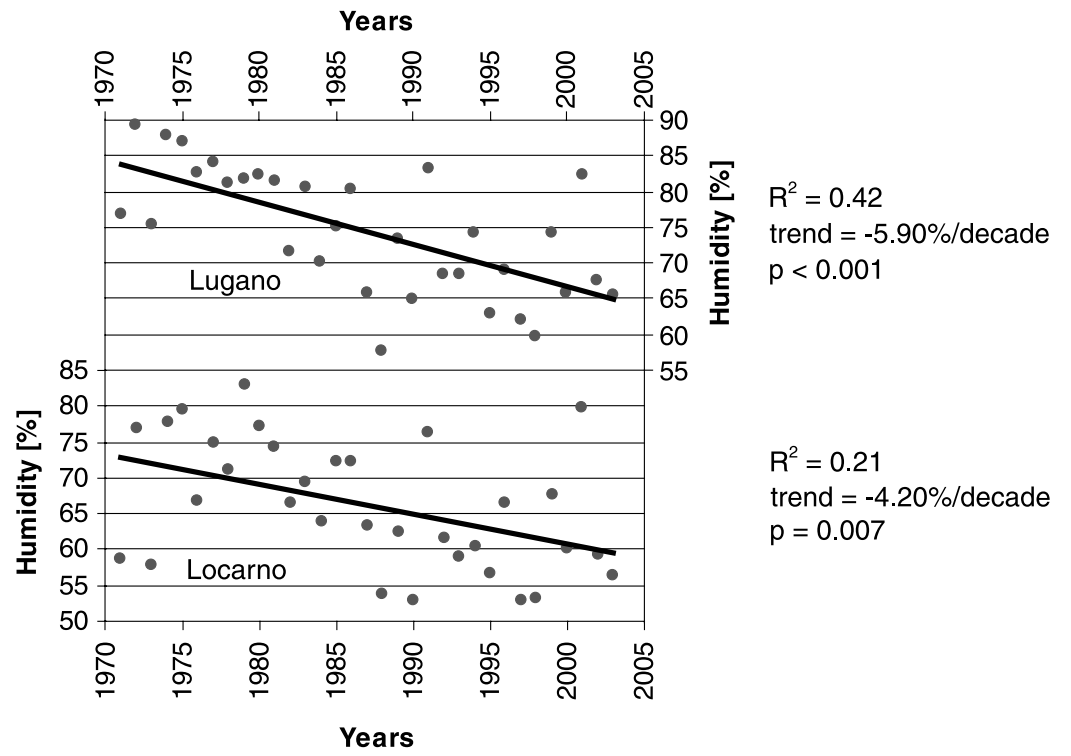

Fig. 6. Relative humidity at $7 \mathrm{am}$ in March in Locarno and Lugano

by +13.8 hours $(+4.9 \%)$ per decade on average. February and March in Lugano in particular had highly significant positive trends: +18 hours $(+7.1 \%)$ and +28.8 hours $(+8.5 \%)$. In Locarno, only in winter was there a significant trend of +8 hours $(+3.3 \%)$, but CFDS again had a highly significant positive trend of +11.9 hours $(+4.5 \%)$ and March a highly significant increase 
Absolute Sunshine duration in March (1971-2003)

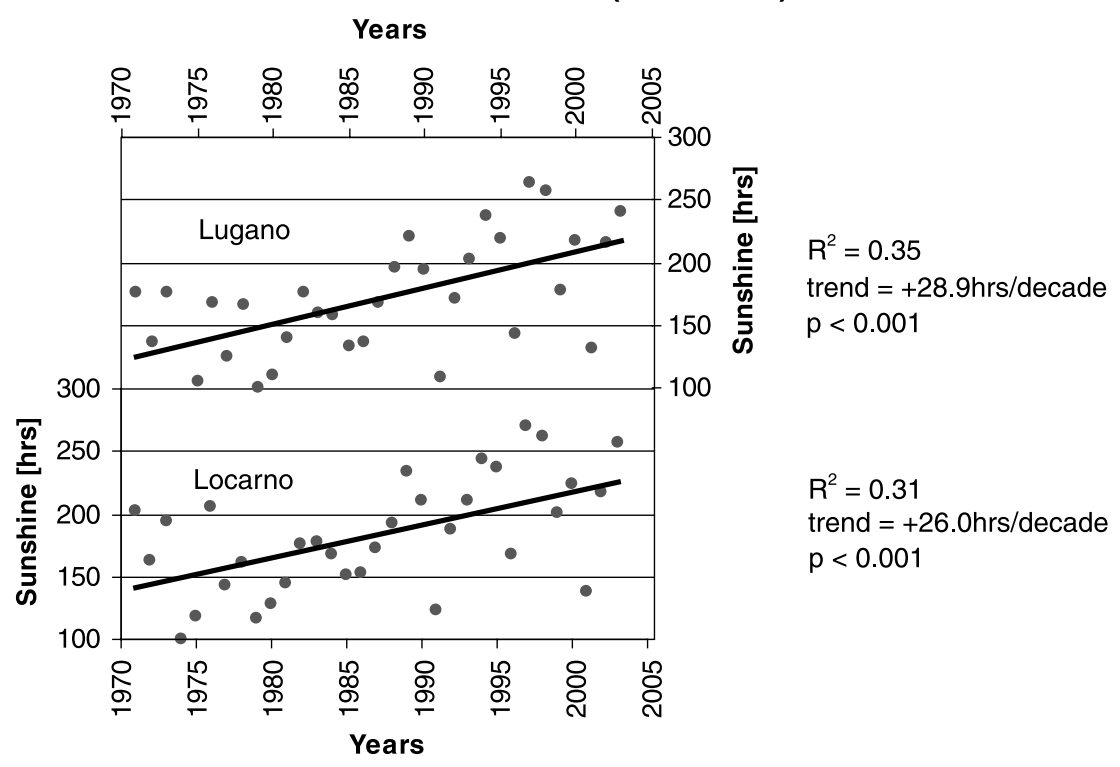

Fig. 7. Absolute sunshine duration in March in Locarno and Lugano of +25.9 hours $(+7.7 \%)$. February exhibited a significant increase of +18.0 hours $(+7.3 \%)$.

There were no annual or seasonal highly significant or significant trends in Foehn events. Foehn situations have remained stable at about 25 events per year, mostly occurring in March and April.

Table 1 shows correlations between the different climatic variables for the most fire prone months and periods, i.e. February, March, April, May, Winter, Spring and CFDS. For all considered periods and both stations, minimum and maximum temperatures were positively correlated. The same was true between precipitation and relative humidity, and between maximum temperatures and sunshine duration. Negative correlations occurred between Foehn, maximum temperatures, sunshine duration and relative humidity at all daily measures.

Precipitation and relative humidity were negatively correlated to sunshine duration as well as with Foehn events, particularly in Winter, Spring, CFDS and March. Foehn and sunshine duration were positively correlated in February, March, Spring and during CFDS. Foehn was also negatively correlated with minimum temperatures in April and with precipitation in Winter, March, May and during CFDS. Foehn was generally positively correlated with maximum temperatures in February and sunshine duration in all other considered periods. Correlation between relative humidity and minimum temperatures was low except in Spring in Lugano. In May, minimum temperatures were negatively correlated with precipitation in Locarno.

\section{Discussion}

The Locarno and Lugano stations are both located in Ticino, southern Switzerland and have collected good quality data. The two stations display consistent and similar trends: minimum temperatures increased, predominantly in spring, and particularly due to the high values in May (Table 1). The same is true for maximum temperatures, but with the highest increase in March. In contrast to the rest of Switzerland, Ticino was different. Both minimum and maximum temperatures increased in Ticino (Figs. 3 and 4), unlike the general warming patterns in Switzerland (Rebetez, 2001), where only minimum temperature exhibit a significant increase, particularly at low elevations. For northern Alpine areas, this phenomenon is due to low-level cloudiness and a moisture-laden lower atmospheric boundary layer (Rebetez and Beniston, 1998). Our results suggest that the increase in maximum temperatures in Ticino could be related to the increase in absolute and relative sunshine duration corresponding to reduced cloudiness.

Recently, more severe episodes with a lack of precipitation have been occurring within the year (Fig. 5). Our analysis shows that the most significant increase is during CFDS, though winter and 
Drought in the context of Forest Fire Research

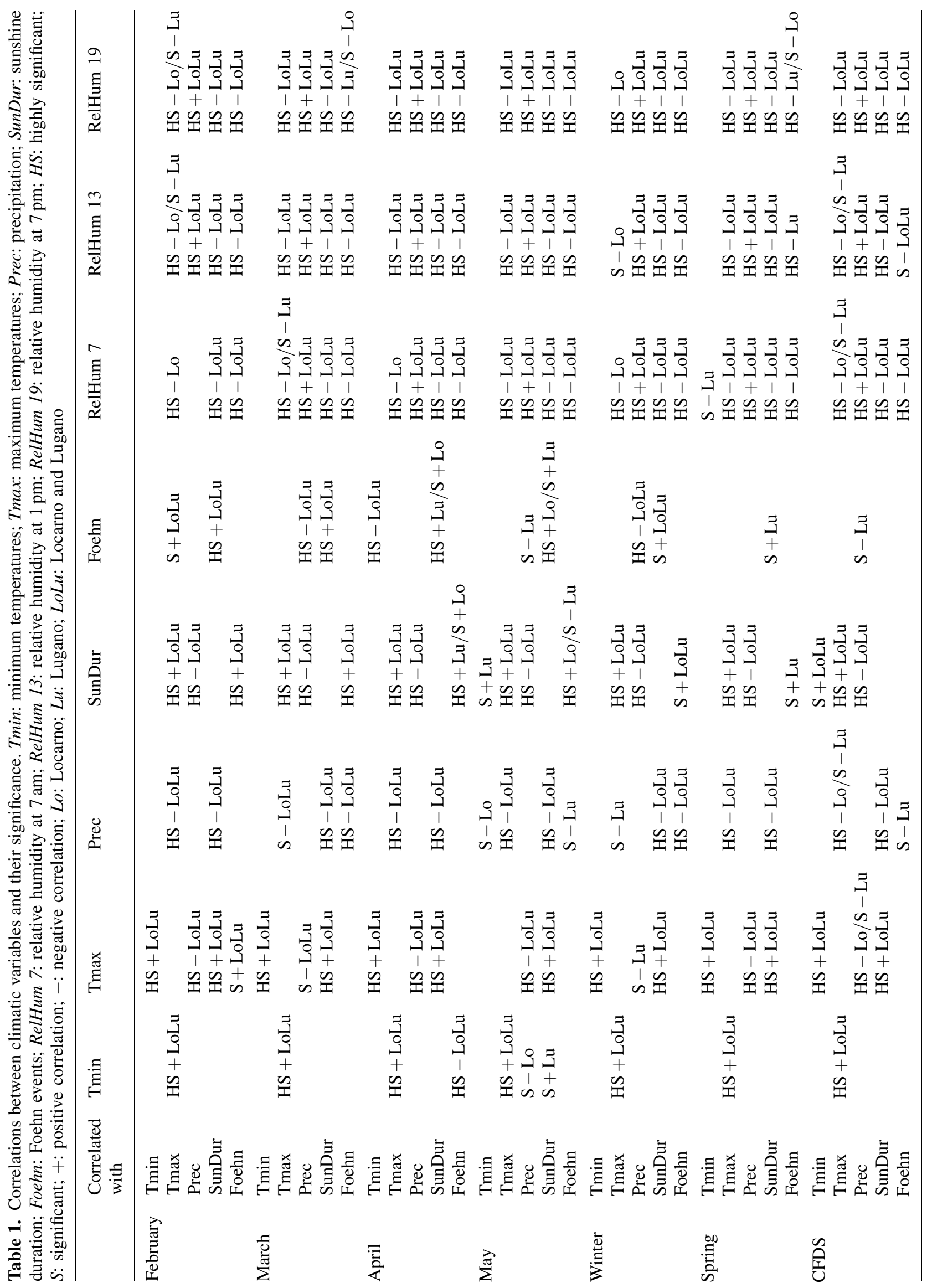


summer also experience slight decreases. Concerning monthly precipitation totals, the largest increase is again in March. In autumn, September and particularly November, precipitation has greatly increased, although the monthly means are not significant (Table 1). It would probably be worth studying extremes during the autumn season.

Relative humidity has been declining consistently for all three daily measures and principally over CFDS. The decrease is most marked in March (Fig. 6). We suggest that the drop in relative humidity is due to the increase in sunshine duration and Foehn rather than to the increase in temperature as traditionally assumed (Table 1).

Sunshine duration increased most strongly during the CFDS, particularly in March (Fig. 7) and, to some extent, in February. This increase in sunshine duration plays a particularly important role as the sun's intensity is increasing by that time of the year, while plants' buds are still closed. This means there is a considerable amount of dead litter (potential fuel) on the forest floor, which is exposed to strong solar radiation, so that it dries out quicker than after leaf cover develops. This phenomenon could be reinforced with Foehn events, which are positively correlated (particularly in February, March and spring) with absolute sunshine duration (Table 1). Relative humidity at all times of the day is also strongly correlated with Foehn events, especially in March (Table 1).

Annual values, both sums and means, are not good drought indicators. We do not observe significant trends in yearly precipitation sums, nor do we detect any trend in Foehn events and sunshine duration (absolute and relative values). However, minimum and maximum temperatures have increased significantly and relative humidity decreased significantly for all daily measures. Yearly sums or averages are not sensitive enough to detect drought episodes. This is particularly true if we consider that a drought can end abruptly within days.

\section{Conclusions}

Our results show that fire proneness related to climatic drought increased over the period 1971-2003 in Ticino, southern Switzerland. March became drier due to the combined effects of increases in minimum and maximum tempera- tures, sunshine duration, and the decrease in relative humidity, and precipitation. CFDS exhibits trends similar to the month of March, with the exception of precipitation.

Annual values are of little use when considering drought in the context of forest fires. Intra-annual phenomena are more appropriate. Furthermore, considering climatic variables other than precipitation has proved valuable, as these variables exhibit interesting trends that are likely to play important roles in fire proneness.

These results are very important in the context of forest fire prevention, even though fires are mostly anthropogenically triggered. Decision makers have to deal with more severe framework conditions than twenty or thirty years ago and should implement appropriate measures. Agroforestry will also need to rethink its role in reducing fuels within the forest boundaries.

Future efforts will need to focus on the connection between the present climatic analyses and forest fires in Ticino in order to determine to what extent climatic drought is implicated in forest fire occurrence, and to what extent human factors play a greater role.

\section{Acknowledgements}

This work has been supported by the European COST Program, Action 719. It is also part of the Forest Investigation Program, a joint project between the Swiss Federal Office of the Environment, Forests and Landscape (BUWAL, Bern) and the Swiss Federal Institute for Forest, Snow and Landscape Research (WSL, Birmensdorf). We are grateful to MeteoSwiss for providing the climatological data, to WSL Sottostazione Sud delle Alpi for data from the Forest Fire Database, to Hans-Peter Roesli and Paolo Ambrosetti, MeteoSwiss Locarno for their help with the quantitative definition of Foehn events, to Norbert Kräuchi and Fawziah Gadallah for their positive and constructive comments and to Silvia Dingwall for assistance with English.

\section{References}

Amiro BD, Stocks BJ, Alexander ME, Flannigan MD, Wotton BM (2001) Fire, climate change, carbon and fuel management in the Canadian boreal forest. Int J Wildland Fire 10: 405-413

Bader S, Kunz P (2000) Climate risks - The challenges for Alpine Regions. Final Scientific Report NRP31. Zürich: VdF. 312 pp

Barry RG, Chorley RJ (2003) Atmosphere, weather and climate. London: Routledge, 472 pp

Bryant EA (1991) Natural Hazard. Cambridge: Cambridge University Press, 336 pp 
Conedera M, Mandallaz D, Bolognesi R, Ambrosetti P (1997) Forest fire research in Switzerland. Part 2: Fire danger prediction in the Southern Part of Switzerland. Int For Fire News 16: 2-6

Conedera M, Marcozzi M, Jud B, Mandallaz D, Chatelain F, Frank C, Kienast F, Ambrosetti P, Corti G (1996) Incendi boschivi al Sud delle Alpi: passato, presente e possibili sviluppi futuri. PNR 31 Report. Zürich: VdF Hochschulverlag, $143 \mathrm{pp}$

Flannigan MD, Stocks BJ, Wotton BM (2000) Climate change and forest fires. Sci Total Environ 262(3): 221-229

Frei C et al (1998) Heavy precipitation processes in a warmer climate. Geophys Res Lett 25(9): 1431-1434

Gillett NP, Weaver AJ, Zwiers FW, Flannigan MD (2004) Detecting the effect of climate change on Canadian forest fires. Geophys Res Lett 31: L18211, doi:10.1029/ $2004 G L 020876$

IPCC (1995) Climate change 1995. Cambridge: Cambridge University Press, $584 \mathrm{pp}$

IPCC (1998) The regional impacts of climate change. Cambridge: Cambridge University Press, 527 pp

IPCC (2001) Climate change 2001: The scientific basis. Cambridge: Cambridge University Press, 892 pp

Johnson EA (1992) Fire and vegetation dynamics: Studies from the North American Boreal Forest. Cambridge: Cambridge University Press, 143 pp

Meyer GA et al (1995) Fire and alluvial chronology in Yellowstone-National-Park - Climatic and intrinsic controls on Holocene geomorphic processes. Geol Soc Am Bull 107: 1211-1230
Rebetez M et al (1997) Climatic warming and debris flows in High Mountain Regions: The case-study of the Ritigraben Torrent (Swiss Alps). Climatic Change 36: 371-389

Rebetez M (1999) Twentieth century trends in drought in southern Switzerland. Geophys Res Lett 26(6): 755-758

Rebetez M (2001) Changes in daily and nightly day-to-day temperature variability during the twentieth century for two stations in Switzerland. Theor Appl Climatol 69: $13-21$

Schmidli J, Frei C (2003) 20th century trends of extreme precipitation conditions in the Swiss Alps. STARDEX Programme. ETH partner report for deliverable D9, $40 \mathrm{pp}$

Smith K (2001) Environmental Hazards: Assessing risk and reducing disasters, 3rd edn. London: Routledge, 420 pp

Tinner W, Hubschmid P, Wehrli M, Ammann B, Conedera M (1999) Long-term forest fire ecology and dynamics in southern Switzerland. J Ecol 87: 273-289

Tinner W, Conedera M, Ammann B, Gäggeler HW, Gedey S, Jones SR, Sägesser B (1998) Pollen and charcoal in lake sediments compared with historically documented wildfires in southern Switzerland since AD 1920. Holocene 8: $31-42$

Wilhite DA (2000) Drought, a global assessment. London: Routledge, 760 pp

Authors' addresses: Michael Reinhard (e-mail: michael. reinhard@wsl.ch) and Martine Rebetez, WSL Swiss Federal Research Institute, P.O. Box 96, 1015 Lausanne, Switzerland; Rodolphe Schlaepfer, EPFL Swiss Federal Institute of Technology at Lausanne, 1015 Lausanne, Switzerland. 